\title{
Photoreactivity of an Exemplary Anthracene Mixture Revealed by NMR Studies, including a Kinetic Approach
}

\author{
Kristina Kristinaityte (D), Mateusz Urbańczyk (D), Adam Mames, Mariusz Pietrzak * and Tomasz Ratajczyk *(D) \\ Institute of Physical Chemistry, Polish Academy of Sciences, PL-01224 Warsaw, Poland; \\ kkristinaityte@ichf.edu.pl (K.K.); murbanczyk@ichf.edu.pl (M.U.); amames@ichf.edu.pl (A.M.) \\ * Correspondence: mpietrzak@ichf.edu.pl (M.P.); tratajczyk@ichf.edu.pl (T.R.)
}

Citation: Kristinaityte, K.;

Urbańczyk, M.; Mames, A.; Pietrzak,

M.; Ratajczyk, T. Photoreactivity of an Exemplary Anthracene Mixture Revealed by NMR Studies, including a Kinetic Approach. Molecules 2021, 26, 6695. https://doi.org/10.3390/ molecules26216695

Academic Editor: Lucia Panzella

Received: 1 October 2021

Accepted: 3 November 2021

Published: 5 November 2021

Publisher's Note: MDPI stays neutral with regard to jurisdictional claims in published maps and institutional affiliations.

Copyright: (c) 2021 by the authors. Licensee MDPI, Basel, Switzerland. This article is an open access article distributed under the terms and conditions of the Creative Commons Attribution (CC BY) license (https:// creativecommons.org/licenses/by/ $4.0 /)$.

\begin{abstract}
Anthracenes are an important class of acenes. They are being utilized more and more often in chemistry and materials sciences, due to their unique rigid molecular structure and photoreactivity. In particular, photodimerization can be harnessed for the fabrication of novel photoresponsive materials. Photodimerization between the same anthracenes have been investigated and utilized in various fields, while reactions between varying anthracenes have barely been investigated. Here, Nuclear Magnetic Resonance (NMR) spectroscopy is employed for the investigation of the photodimerization of two exemplary anthracenes: anthracene (A) and 9-bromoanthracene (B), in the solutions with only $\mathbf{A}$ or $\mathbf{B}$, and in the mixture of $\mathbf{A}$ and $\mathbf{B}$. Estimated $k$ values, derived from the presented kinetic model, showed that the dimerization of $\mathbf{A}$ was 10 times faster in comparison with $\mathbf{B}$ when compounds were investigated in separate samples, and 2 times faster when compounds were prepared in the mixture. Notably, the photoreaction in the mixture, apart from AA and BB, additionally yielded a large amount of the $\mathbf{A B}$ mixdimer. Another important advantage of investigating a mixture with different anthracenes is the ability to estimate the relative reactivity for all the reactions under the same experimental conditions. This results in a better understanding of the photodimerization processes. Thus, the rational photofabrication of mix-anthracene-based materials can be facilitated, which is of crucial importance in the field of polymer and material sciences.
\end{abstract}

Keywords: anthracene; UV-illumination; photodimerization; NMR; kinetics

\section{Introduction}

Polycyclic aromatic hydrocarbons, commonly known as acenes, are a significant class of organic molecules built from fused benzene rings which are arranged linearly [1]. Their interesting chemical and physical properties have attracted the attention of researchers, and many various organic synthetic routes, as well as experimental and theoretical studies, have been devoted to this class of organic compounds [2]. Moreover, acenes are widely utilized in many branches of material sciences and medicine [3-5].

Among acenes, anthracene and its derivatives are of central interest, which is primarily due to their relatively easy synthesis and purification, which facilitates their potential applications in various fields of chemistry, material sciences and biology [6-8]. In particular, one of the most important research issues regarding anthracenes is related to their photoreactivity, which, in principle, involves two scenarios of [4+2] and [4+4] photoinduced cycloadditions [9-11].

Regarding the $[4+2]$ photoinduced scenario, the reaction of anthracenes with singlet oxygen is the most investigated issue, as this reaction yields endoperoxides (EPOs), which are of central importance in many fields [11-14]. For example, EPOs are used in organic synthesis for the generation of hydrogen peroxide under mild conditions [15]. In medicine and biology, the cycloaddition of oxygen to anthracenes can be used in photodynamic therapy in order to combat malignant cells with a controlled release of oxygen species [16], for detecting singlet oxygen in biological systems [17], and for optical imaging [18]. 
Concerning the $[4+4]$ scenario, the photochemistry of anthracene dimerization is of central interest. In principle, the photodimerization occurs upon irradiation in two different wavelength $(\lambda)$ windows. The less energetic $\lambda(>300 \mathrm{~nm})$ is usually chosen for photodimerization in order to avoid a competitive photodissociation process, which occurs at a shorter $\lambda(<300 \mathrm{~nm})$ regime $[18,19]$. Recently, there has been a growing interest in shifting the absorption band to an even higher $\lambda$ regime $[18,19]$ in order to avoid damage to the surrounding matrix and biological tissues caused by UV light. In the precise wavelength-dependent study, Kislyak et al. [19] presented a detailed photokinetic framework highlighting the importance of the initial conditions for the reaction pathway.

Regarding the reaction pathway, it is unquestionable that the singlet excited state is involved in the reaction mechanism. For example, one of the possible mechanisms of anthracene dimerization involves three steps. At first, the anthracene molecule is excited, then a pair of excited and unexcited molecules is formed. In the third step, this pair reacts, forming a dimer $[19,20]$. However, fluorescence is possible, and the excimer can split up into two unexcited molecules. In this context, dimerization and fluorescence are two competitive processes. This basic scenario can sometimes be more complex and can involve various transient species. For example, many issues concerning the excimer are still under investigation [21]. The issue of the photodimerization of anthracenes has been addressed many times. Many studies have been devoted to the kinetics and reactivity of substituted anthracenes, which depends on the electronic properties of the substituent. Furthermore, different isomers of the dimer can be formed $[9,22,23]$. Therefore, the regio- and enantioselectivity of anthracene photodimerization has been investigated comprehensively, both via experiment and quantum chemistry calculations [24-28].

Regarding the applications of anthracenes, tunable luminescence and easy charge transfer coupled with the unique ability of the reversible dimerization make anthracenes valuable building blocks for the generation of light responsive materials $[9,29,30]$. This includes various polymeric materials [30,31], such as intelligent shape memory polymers [32], as well as soft materials, such as photoresponsive hydrogels [16] and liquid crystals [33]. Hence, the main applications cover a vast number of fields, including tissue engineering [30], optoelectronic devices [33] such as organic light-emitting diodes or transistors [34], sensors for metal ion detection [35], molecular containers for catalysis or drug delivery [36] and photomedicine, where these compounds can be used as intracellular $\mathrm{pH}$ probes [37], DNA-based hybridization sensors [38] and other biosensors [39]. According to the latest results, anthracene derivatives have even been suggested as potential candidates for applications in laser photonics [40] and as smart optical materials [41].

Taking into account the vast majority of data concerned with the photochemistry of anthracenes, one can notice that previous studies and applications have focused on the photoreactions leading to homodimers, i.e., the dimers created from two identical monomer molecules. Interestingly, a few examples of photoreactions between anthracenes and higher acenes have already been presented, but no comprehensive kinetics have been mentioned [6]. This is quite an interesting situation, as the reaction between different anthracenes raises many interesting questions. It is intriguing also from the application point of view, as a more complex and functional systems may have the potential to be photo fabricated.

Mixtures containing various anthracene molecules can produce both homo- and mixdimers upon irradiation. The kinetics of the formation of the mixdimers cannot be determined from the kinetics of the formation of the homodimers directly. Therefore, the comparison of the kinetics of competing photoreactions conducted in the mixture of substrates reveals the relative reactivity of all reacting molecule pairs. It is worth mentioning that the kinetics of photodimerization is very sensitive to the experimental conditions, in particular, the illumination. The importance of the initial conditions is highlighted in the study of Kislyak and co-workers, where even the effect of continuous-wave light sources versus pulsed lasers is discussed [19]. Therefore, simultaneous measurement of kinetic parameters of photodimerization in a mixture is an advantage, as it provides the same 
experimental conditions for all the reactions and allows us to analyze the relative reactivity in a straightforward manner. The comparison of the photoreactivity of different photoactive compounds is an important issue, and the methodology that can help to reproduce the same illumination conditions is very often addressed in the literature in the context of photoreactions [42].

To conclude the introduction, in the present work, we focus on the investigation of photoreactions in the mixture of anthracenes. To do this, we employ ${ }^{1} \mathrm{H}$ NMR spectroscopy, which is being more and more often employed in the field of photochemistry and reaction monitoring [43-47]. We demonstrate that a simple NMR approach can easily deliver data which enables us to obtain insights into the kinetics of the photoreactivity between varying anthracenes. However, as we demonstrate that the NMR approach is easy to employ for photoreaction monitoring, it also has some pitfalls, which will be discussed in this manuscript.

\section{Results and Discussion}

\subsection{Comparison of $A$ and $B$ in Separate Samples}

We begin our research with the investigation of the individual models of $\mathbf{A}$ and $\mathbf{B}$. The choice of $\mathbf{A}$ is obvious - it can be treated as a reference system, as a large amount of data about the photodimerization of anthracenes is available [2,6,9]. Regarding $\mathbf{B}$, it can be easily functionalized via metalation or cross-coupling reactions [48]. Thus, $\mathbf{B}$ is a good starting point for the development of more functional photoreactive monomers [49]. Moreover, $\mathbf{B}$ is also utilized as an initiator in the atom transfer radical polymerization (ATRP), which can help to control the polymerization of styrene [23].

The ${ }^{1} \mathrm{H}-\mathrm{NMR}$ monitoring of our samples revealed that all investigated compounds form dimers upon $365 \mathrm{~nm}$ irradiation, as is typically reported for anthracene and its derivatives (Figure 1). Because of the large aromatic $\pi$-surface area, $\mathbf{A}$ has a relatively low electronic energy gap $\left(\pi-\pi^{*}\right)[8,18]$. Therefore, the molecule can easily be excited by irradiation using ultraviolet light. A wavelength of $365 \mathrm{~nm}$ was chosen in order to conduct dimerization only, and to avoid the undesirable side reactions, as well as the reverse reaction — the cleavage of a formed dimer [50].

a)
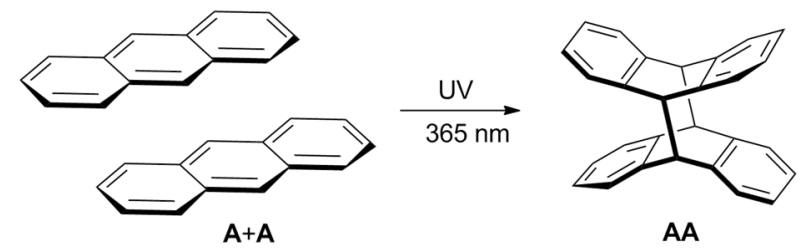

b)
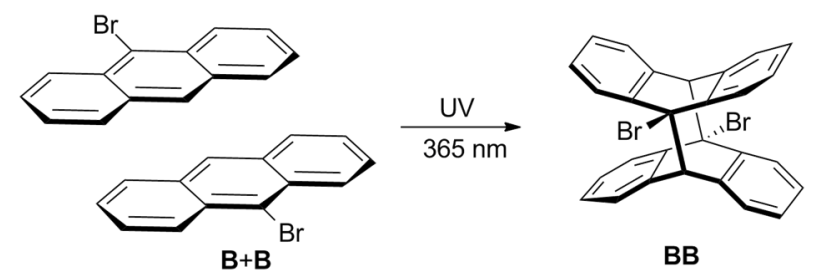

Figure 1. Photodimerization of (a) anthracene (A) and of (b) 9-bromoanthracene (B). For $\mathbf{B}$ only trans isomer is presented as we suppose that this isomer was obtained in the case of our research.

The signals from these homodimers are clearly visible in the ${ }^{1} \mathrm{H}$ NMR spectra, which is presented in the next part of the manuscript (see Section 2.3). In the case of $\mathbf{A}$, only one dimer is possible, and its signals appear as multiplets at 6.93 and $6.81 \mathrm{ppm}$, and as the singlet at $4.55 \mathrm{ppm}$. In the case of $\mathbf{B}$, two possible isomers of $\mathbf{B}$ dimers could be formed. However, the ${ }^{1} \mathrm{H}$ NMR spectra have revealed that only one product is present upon illumination in our case. According to the literature data, the dimer with trans located $\mathrm{Br}$ atoms (head-to-tail configuration) has been identified in previous studies [22,51]. Therefore, we assume that the resonances of a doublet at $7.76 \mathrm{ppm}$, a multiplet at $6.96 \mathrm{ppm}$ 
and a singlet at 5.35 ppm belong to the head-to-tail isomer. It is worth noting that the line at $5.35 \mathrm{ppm}$ is very close to the residual proton signal of the solvent $\mathrm{CD}_{2} \mathrm{Cl}_{2}(5.32 \mathrm{ppm})$ and was not used for qualitative analysis.

In order to obtain insights into the photokinetics of dimer formation, changes in the concentration of the substrate and the products during irradiation were analyzed. The NMR monitoring experiments were conducted at substrate concentrations equal to $4.5 \mathrm{mM}$. The reaction curves derived from ${ }^{1} \mathrm{H}-\mathrm{NMR}$ spectra are compared in Figure 2. Data were fitted using the following equations:

$$
\begin{aligned}
& \frac{d[\mathrm{~A}]}{d t}=-k_{\mathrm{A}}[\mathrm{A}] \\
& \frac{d[\mathrm{AA}]}{d t}=k_{\mathrm{A}} \frac{[\mathrm{A}]}{2}
\end{aligned}
$$

where $k_{\mathrm{A}}$ is a kinetic constant for a dimerization reaction with $\mathbf{A}$ and AA corresponding to the monomer and the dimer, respectively. In the case of $\mathbf{B}$, an additional oxygenation reaction of the monomer occurred, which had to be considered for the kinetic fit. Because of this, the equations had to be modified in this way:

$$
\begin{gathered}
\frac{d[\mathrm{~B}]}{d t}=-k_{\mathrm{B}}[\mathrm{B}]-k_{\mathrm{BO}}[\mathrm{B}], \\
\frac{d[\mathrm{BB}]}{d t}=k_{\mathrm{B}} \frac{[\mathrm{B}]}{2}, \\
\frac{d[\mathrm{BO}]}{d t}=k_{\mathrm{BO}}[\mathrm{B}]
\end{gathered}
$$

where $\mathbf{B}$ and $\mathbf{B B}$ correspond to the monomer and the dimer, respectively, while $\mathbf{B O}$ is the oxidized form of $\mathbf{B}$.
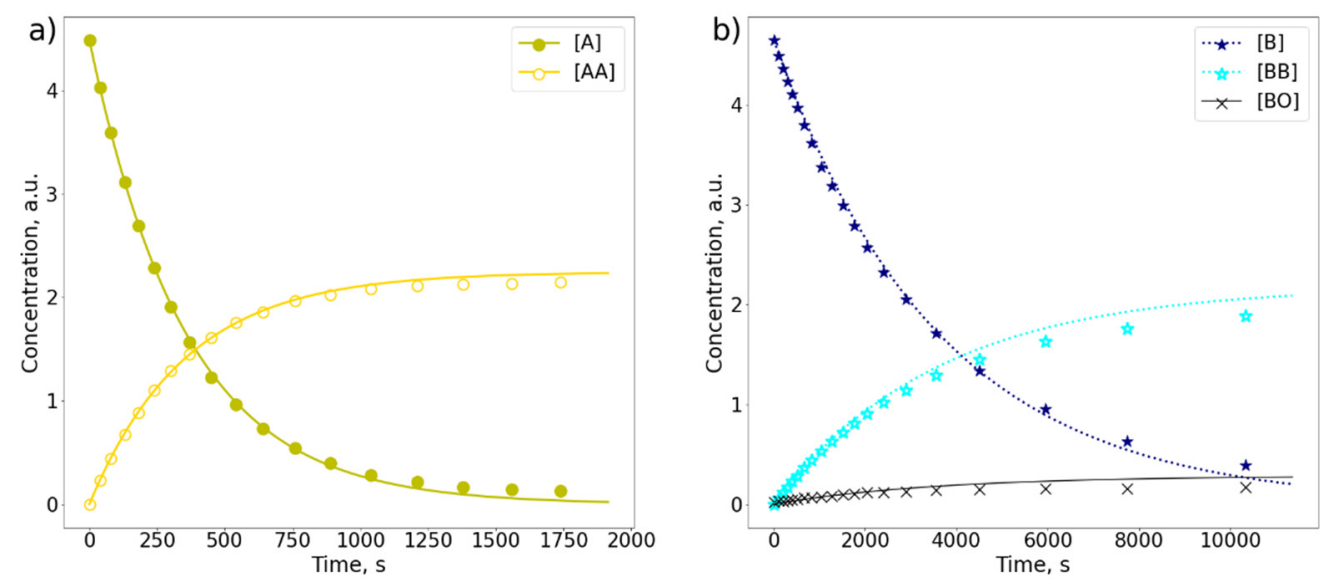

Figure 2. The comparison of photodimerization curves $(\lambda=365 \mathrm{~nm})$ derived from $400 \mathrm{MHz}{ }^{1} \mathrm{H}-\mathrm{NMR}$ spectra of (a) anthracene (A) and (b) 9-bromoanthracene (B) in separate samples each of $4.5 \mathrm{mM}$ concentration in $\mathrm{CD}_{2} \mathrm{Cl}_{2}$. Two products are observed: a dimer of $\mathbf{A}(\mathbf{A A})$ and a dimer of $\mathbf{B}(\mathbf{B B})$.

The assessed reaction rates revealed that the photodimerization of $\mathbf{B}$ was about 10 times slower compared to the dimerization process of $\mathbf{A}$, with corresponding kinetic constants equal to $2.8 \times 10^{-3} \mathrm{~s}^{-1}$ and $2.6 \times 10^{-4} \mathrm{~s}^{-1}$ for $\mathbf{A}$ and $\mathbf{B}$, respectively. It has been noticed that $\mathbf{A}$ can be almost fully consumed in about $1800 \mathrm{~s}$, while $\mathbf{B}$ in more than $10,000 \mathrm{~s}$. It has to be stressed that the model we used has been simplified. The reaction is considered to be irreversible, which seems to be a good assumption, because the reverse reaction usually occurs at much higher temperatures or under irradiation with short-wave UV light $[3,52,53]$. The obtained kinetic data are valid only for our specific irradiation 
conditions. Therefore, they can be used only as relative numbers showing the difference in reactivity between reacting molecules.

According to the literature, the overall (apparent) reaction order with respect to the anthracene concentration can vary between 0 and 2, depending on the initial conditions [19]. However, S. Dong and co-workers in their review stated that dimerization is a second-order reaction [6]. Moreover, it was also noted that since polymerization is a first-order reaction, competition between polymerization and dimerization should be concentration dependent, and that at low acene concentrations, polymerization is preferred [6]. Based on our results from fitting procedure and analysis of the residual as a function of the reaction order, the minimum of residual for both reactions was at order 1. (Figure S1). Therefore, in our case, the dimerization of both $\mathbf{A}$ and $\mathbf{B}$ can be considered as a first-order reaction.

A fitting model included only the dimerization process, assuming that our experimental conditions were set in such a way that all side reactions, as well as oxygenation, could be ignored. The detailed mechanism of dimerization is thoroughly described by Kislyak's group, including all possible reaction pathways characterized by corresponding individual $k$ values [19]. The same group also investigated the equilibrium between dimerization and cleavage of the dimer [50]. They developed a kinetic model, which could be applied under a wide range of reaction conditions including variations in the initial concentrations of $\mathbf{A}$ and the dimer of A (AA) as well as $\lambda$ [50]. According to this group, one of the strengths of a kinetic model if fed with sufficient variations in experimental data is to correct for inconsistencies, as sometimes it is difficult to assess purely experimentally.

The reactivity of anthracenes and their derivatives is influenced by the presence of an electron-withdrawing or electron-donating group in the anthracene unit, as the reactivity of these compounds is mainly determined by their electronic properties [3,52]. A can be considered as a reference molecule, where the $\mathrm{H}$ atom is present as neither an electrondonating, nor a withdrawing substituent, whereas $\mathbf{B}$ has an electron-withdrawing $\mathrm{Br}$ atom. It is known that the electron-withdrawing groups, also known as deactivating groups, reduce dimerization reactivity in the case of $4+2$ Diels-Alder cycloaddition [3,53,54]. One can thus speculate that the electron-withdrawing property of the $\mathrm{Br}$ atom is the reason why the photodimerization process of $\mathrm{B}$ is slower in comparison to the photodimerization of $\mathrm{A}$.

In this study, a few experimental challenges were also encountered, including homogeneous illumination, solubility, oxygenation, and volatility of the solvent and that is the reason why external irradiation of the sample was chosen. There is a variety of in-situ illumination methods presented in the literature [55-57] and their advantages compared to ex-situ illumination, especially in terms of experiment time and amount of collected data points, lead to a more accurate evaluation of the reaction mechanism [55]. In spite of this fact, experimental inconsistencies are easier to handle using external irradiation.

\subsection{The Effect of Experimental Conditions}

The easiest parameter to control is the volume of the sample. In order to obtain homogeneous irradiation, it is important to illuminate the entire sample and to avoid convection, which can be expected to change the reaction rate. More details are presented in the supportive information and in Figure S2. The biggest challenge is to obtain the same conditions between different experiments, in particular, the oxygenation level of the samples.

\subsubsection{The Effect of the Concentration of Anthracenes}

The solubility of $\mathbf{A}$ and its dimer in acetonitrile, which was used as a solvent, appeared to be too low. This resulted in precipitation after irradiation, which affected the kinetics of the photodimerization. Taking that into account, deuterated dichloromethane $\left(\mathrm{CD}_{2} \mathrm{Cl}_{2}\right)$ was used as a solvent for the next experiments. First of all, the solubility of $\mathrm{A}$ in $\mathrm{CD}_{2} \mathrm{Cl}_{2}$ was significantly higher. Secondly, the $\pi-\pi$ and hydrogen bond interactions between the solvent and aromatic anthracenes is not an essential issue in this solvent. 
Based on the visual observations of the solubility of the substrate, the initial concentration of $\mathbf{A}$ was set to $3 \mathrm{mg} / \mathrm{mL}(16.8 \mathrm{mM})$. The reaction curves of two samples (sample 1 and sample 2) derived from the ${ }^{1} \mathrm{H}-\mathrm{NMR}$ spectra were compared (Figure $3 \mathrm{a}$ ) in order to check the repeatability of the experiment. At the beginning, the photodimerization processes in both samples occurred in the same manner. However, after the consumption of about $50 \%$ of the substrate, the kinetics of the dimer formation started to differ. The results suggested that the solubility of the product was not sufficient. The precipitation of the product could also be detected visually. Hence, the concentration of A was further reduced (Figure 3) until no precipitation of the product was observed, neither visually nor from the reaction curves.
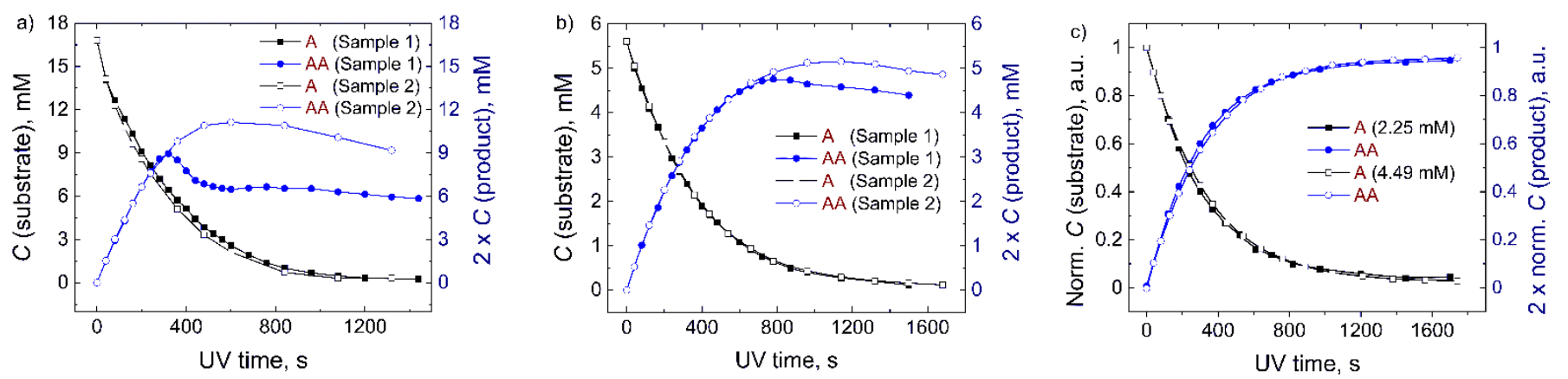

Figure 3. The effect of the precipitation on the photodimerization curves $(\lambda=365 \mathrm{~nm})$ derived from $400 \mathrm{MHz}{ }^{1} \mathrm{H}-\mathrm{NMR}$ spectra of anthracene (A) and its dimer (AA). Each experiment was repeated on two separate samples (sample 1 and sample 2) prepared from the same batch. The precipitation was observed $(\mathbf{a}, \mathbf{b})$ until the concentration of anthracene was reduced to $4.5 \mathrm{mM}$, and no further effect of concentration on kinetics was noticed (c).

The comparison of two separate experiments for the same system resulted in the same decay curve only when the initial concentration of $\mathbf{A}$ was $4.5 \mathrm{mM}(0.8 \mathrm{mg} / \mathrm{mL})$ or lower. Moreover, the further dilution of the sample did not show any significant effect on the kinetics of the photodimerization. The comparison of the kinetics when the concentration of A was $4.5 \mathrm{mM}$ and $2.25 \mathrm{mM}$ is demonstrated in Figure 3c. It is worth mentioning that the irradiation curves shown in Figure 3 allow us to estimate the solubility of the reaction product. In this case, the value of about $4.5 \mathrm{mM}$ corresponds to a saturated solution of the anthracene dimer (AA).

Crystallization of the product can be directly observed in the NMR sample tube on the walls, which were directly irradiated (Figure S3). This shows that during the illumination, a concentration gradient of products and substrates is present in the solution. The sample volume is not stirred, and therefore, the estimated values of the solubility of the product described above could contain an error.

An analogous trend was observed for $\mathbf{B}$. This means that the system works in a fairly repeatable manner if the oxygen level in the samples is maintained the same. Low pressure/vacuum (LPV) NMR tubes equipped with a J. Young valve not only allowed us to solve the issue of the volatile solvent, but also helped us to eliminate or significantly reduce the risk of oxygen getting into the sample.

\subsubsection{The Effect of Oxygenation of the Sample}

According to the literature, anthracene exposed to air and light would also undergo an oxidation reaction to yield EPOs. The mechanism of these kinds of photochemical oxidation reactions proceeds via two possible routes. The first is based on the electron transfer from the first excited singlet state of $\mathbf{A}$ to the oxygen in the ground state. The other pathway involves a triplet state of $\mathbf{A}\left({ }^{3} \mathrm{~A}\right)$ and is based on energy transfer. During this mechanism, a triplet sensitizer is usually required to transfer its energy from ${ }^{3} \mathrm{~A}$ to ${ }^{3} \mathrm{O}_{2}$ to form singlet oxygen ${ }^{1} \mathrm{O}_{2}$, which subsequently reacts with acene to form EPOs [6]. Most research is done on the shorter acenes because longer conjugations lead to faster 
oxidation by air, and thus, the purification of the post-reaction mixture is more difficult [18]. Several groups have utilized density functional theory (DFT) calculations, showing that the reactivity of acenes originates from the increased diradical character of longer acenes [6].

To investigate the effect of oxygen, two samples of $\mathbf{A}$ and $\mathbf{B}(2.25 \mathrm{mM})$ were deliberately exposed to oxygen by opening an NMR tube for about $30 \mathrm{~s}$. The results were compared to those derived from the identical deoxygenated samples. A completely different behavior was observed for oxygenated and oxygen-free samples. The presence of oxygen could be tracked by comparing the consumption of the substrate in oxygenated and deoxygenated samples, which can be seen from the reaction curves (Figure 4), as well as directly from the ${ }^{1} \mathrm{H}-\mathrm{NMR}$ spectra (Figure 5). In the cases of both $\mathbf{A}$ and $\mathbf{B}$, it is seen that the substrate is consumed significantly faster in the samples with oxygen compared to the ones without exposure to oxygen.

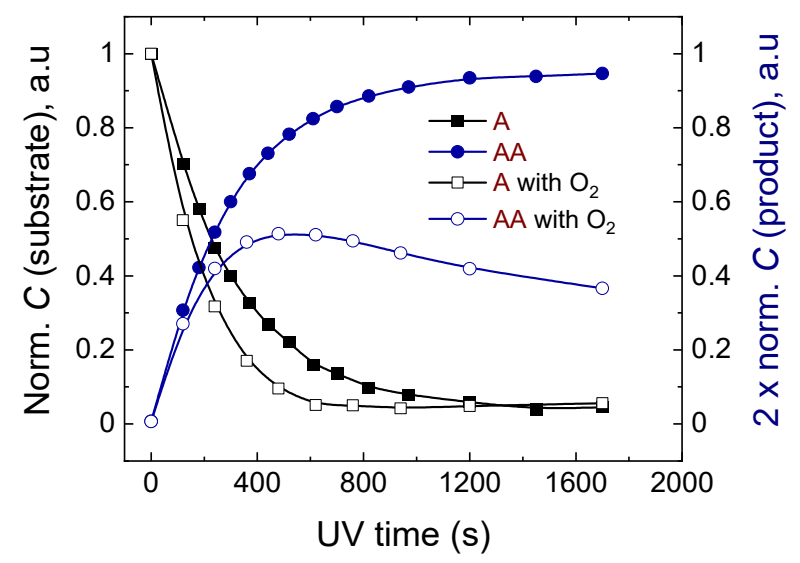

Figure 4. The effect of oxygenation of the sample on the photodimerization curves $(\lambda=365 \mathrm{~nm})$ derived from $400 \mathrm{MHz}{ }^{1} \mathrm{H}-\mathrm{NMR}$ spectra of anthracene (A).

Moreover, as witnessed by the reaction curves of $\mathbf{A}$ and its dimer AA, only about $50 \%$ of the substrate converts to the product, and at the end of the photodimerization reaction, a slight reappearance of the substrate as well as consumption of the dimer is observed. The effect of oxygenation could also be observed by the appearance of additional peaks in the ${ }^{1} \mathrm{H}$-NMR spectra (Figure 5). Two resonances from anthraquinone were observed at 7.83 and $8.29 \mathrm{ppm}$. The peaks were confirmed by registering the ${ }^{1} \mathrm{H}-\mathrm{NMR}$ spectra of anthraquinone (Figure S4). For more details, please see the Supporting Information (SI, pages 4-6). The existence of anthraquinone suggests that EPOs were generated in our sample, as EPO decomposition leads to the anthraquinone systems [15].

Supported by the results, it can be concluded that evaluation of the required experimental conditions and their influence on the photochemical reactions of anthracenes is essential in order to ensure that the entire setup works in a repeatable manner. This means that the quantitative data can be compared for systems with different compounds.

\subsection{Comparison of $A$ and $B$ in the Mixture}

The reaction rate calculated for the sample containing only one compound will be different under different experimental setups. This is because the maintenance of the same experimental conditions is sometimes difficult to achieve. Thus, in order to develop a more reliable approach, for the comparison of the photoreactivity of various anthracenes, we further moved on to experiments with mixtures what is the main part of this study.

Samples containing two anthracene derivatives were investigated. Such an approach seemed to be a more reliable one, as the dimerization of both substrates took place in the same sample, meaning that photoreactions were monitored under the exact same conditions. Moreover, in the system with two compounds, the formation of three products was observed in the NMR spectra: the dimer of $\mathbf{A}(\mathbf{A A})$, the dimer of $\mathbf{B}(\mathbf{B B})$ and the dimer of $\mathbf{A}$ and $\mathbf{B}$ (AB) (Figure 6). 

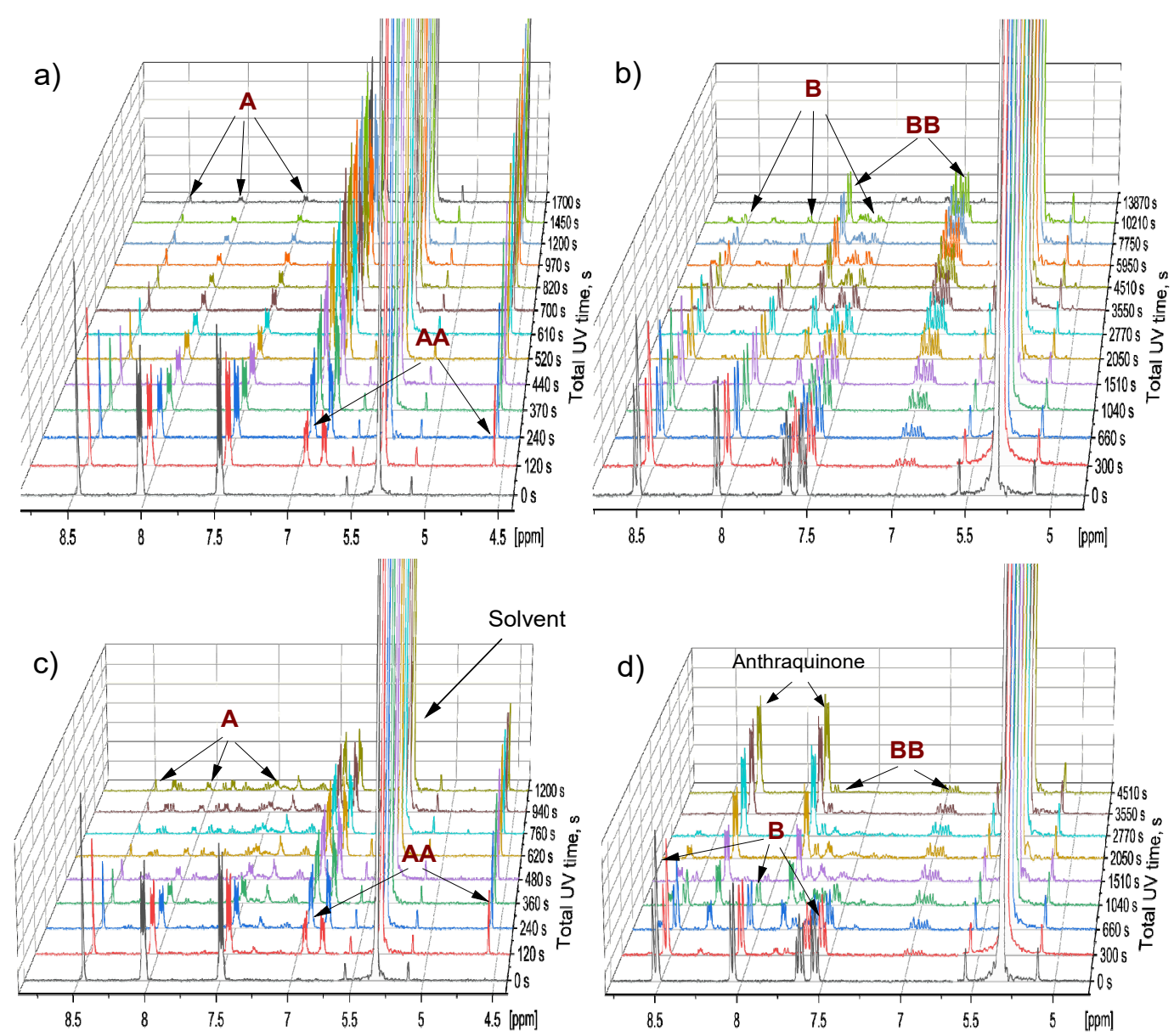

Figure 5. The $400 \mathrm{MHz}{ }^{1} \mathrm{H}-\mathrm{NMR}$ spectra of anthracene (A), dimer of anthracene (AA), 9-bromoanthracene (B) and dimer of 9-bromoanthracene $(\mathbf{B B})$ in: $(\mathbf{a}, \mathbf{b})$ deoxygenated samples and $(\mathbf{c}, \mathbf{d})$ samples with oxygen at different reaction times, i.e., total time of UV illumination $(\lambda=365 \mathrm{~nm})$.

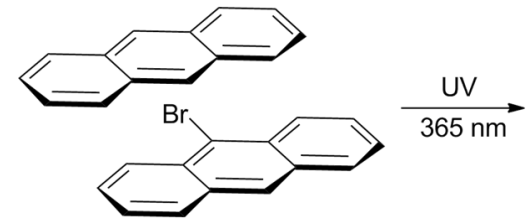

$A+B$

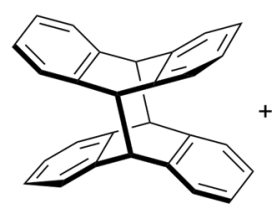

AA

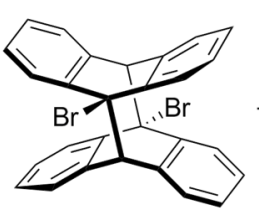

BB

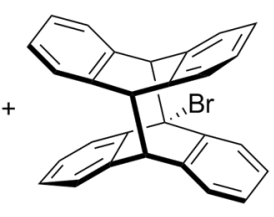

$A B$

Figure 6. Photodimerization of anthracene and 9-bromoanthracene in the mixture. The reaction gives three possible products as a dimer $\mathbf{A A}, \mathbf{A B}$ and $\mathbf{B B}$.

The resonances of $\mathbf{A A}$ and $\mathbf{B B}$ appeared at the same ppm as in the samples with one compound, only this time overlapping with each other or with the resonances from $\mathbf{A B}$. The doublet of $\mathbf{A B}$ at $7.78 \mathrm{ppm}(\mathbf{A B}(\mathrm{P} 1))$ interferes with the doublet of $\mathbf{B B}$ at $7.76 \mathrm{ppm}$ $(\mathbf{B B}(\mathrm{P} 1))$. The signal from the aromatic part of $\mathrm{AB}$ overlaps with the multiplet of $\mathbf{B B}$ at $6.96 \mathrm{ppm}(\mathbf{B B}(\mathrm{P} 2))$ as well as with the signals from $\mathbf{A A}$ at $6.93 \mathrm{ppm}(\mathbf{A A}(\mathrm{P} 1))$ and $6.81 \mathrm{ppm}$ (AA(P2)). Similar to the singlet of $\mathbf{B B}$ at $5.35 \mathrm{ppm}(\mathbf{B B}(\mathrm{P} 3))$, a singlet of $\mathbf{A B}$ is also observed close to the solvent peak at $5.27 \mathrm{ppm}(\mathrm{AB}(\mathrm{P} 2))$. Finally, the doublet of doublets at $4.64 \mathrm{ppm}$ $(\mathbf{A B}(\mathrm{P} 3))$ and $4.52 \mathrm{ppm}(\mathbf{A B}(\mathrm{P} 4))$ from the protons at the 10 and $10^{\prime}$ positions of the dimer AB (Figure 7) appear at the same region as singlet of AA at $4.55 \mathrm{ppm}(\mathbf{A A}(\mathrm{P} 3))$, for which the integral can be calculable, even if the signals are slightly overlapped.

The analysis of mixture kinetics was more complex because most of the chemical shifts of $\mathbf{A B}$ protons were either in the same range as chemical shifts of $\mathbf{A A}$ and $\mathbf{B B}$ dimers, or 
too close to the solvent peak to be distinguishable. Two types of mixture with a molar ratio of $\mathbf{A}$ to $\mathbf{B}$ equal to 1:1.3 (Figure 8a) and 1:2.3 (Figure 8b) were investigated.

a)

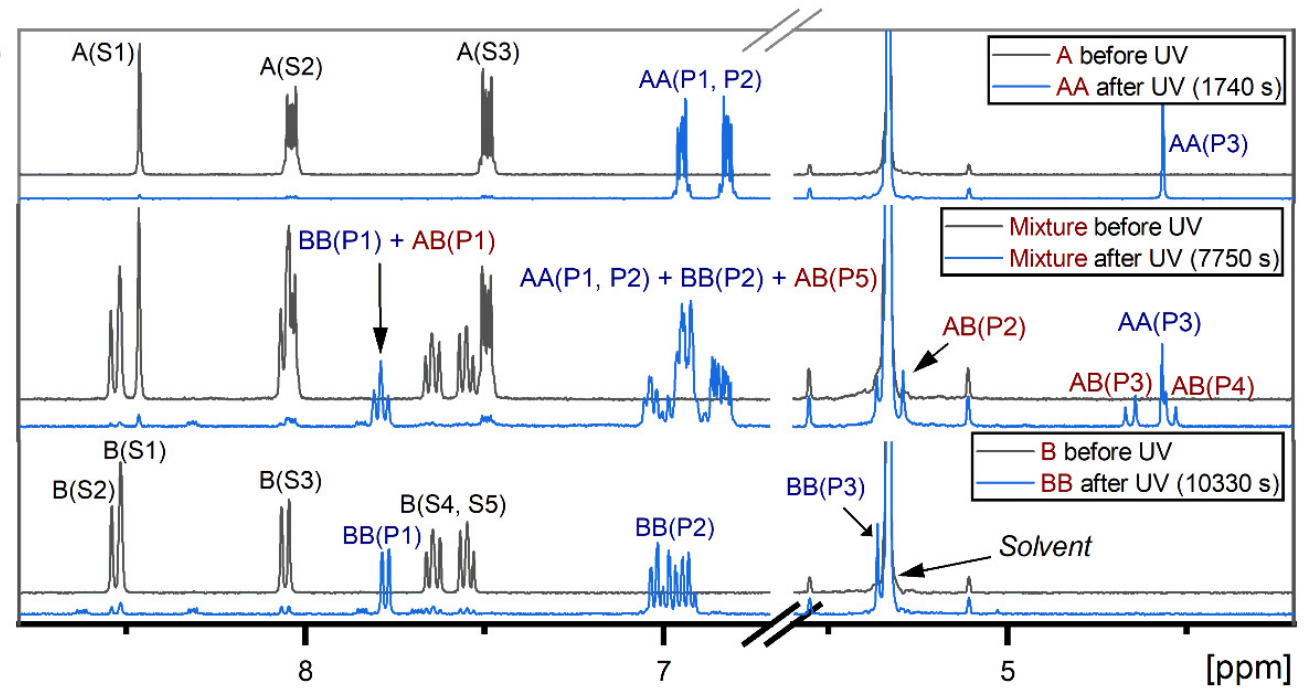

b)

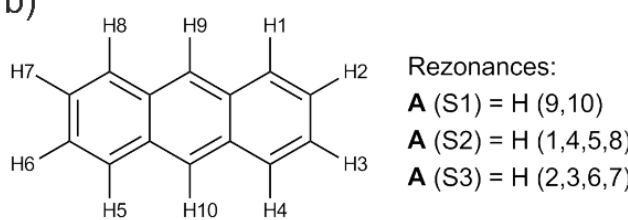

Anthracene A

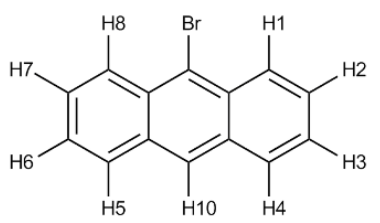

Rezonances:

$B(\mathrm{~S} 1)=\mathrm{H}(10)$

B $(\mathrm{S} 2)=\mathrm{H}(1,8)$

B $(\mathrm{S} 3)=\mathrm{H}(4.5)$

B $(\mathrm{S} 4)=\mathrm{H}(2,7)$

9-bromo anthracene B
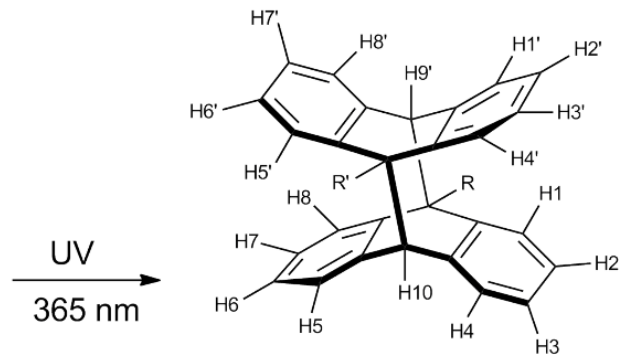

Anthracene dimers:

AA R=H9; $\mathrm{R}^{\prime}=\mathrm{H}_{10} 0^{\prime}$

AB R=Br; $\mathrm{R}^{\prime}=\mathrm{H}^{10}$

BB $\mathrm{R}=\mathrm{Br} ; \mathrm{R}^{\prime}=\mathrm{Br}$
Rezonances:

AA $(P 1)=H\left(1,4,5,8,1^{\prime}, 4^{\prime}, 5^{\prime}, 8^{\prime}\right)$

AA $(P 2)=H\left(2,3,6,7,2^{\prime}, 3^{\prime}, 6^{\prime}, 7^{\prime}\right)$

AA $(P 3)=H\left(9,10,9^{\prime}, 10^{\prime}\right)$

$A B(P 1)=H(1,8)$

$A B(P 2)=H\left(9^{\prime}\right)$

AB (P3 and P4) $=\mathrm{H}\left(10,10^{\prime}\right)$

AB $(P 5)=H(2,3,4,5,6,7$

$\left.1^{\prime}, 2^{\prime}, 3^{\prime}, 4^{\prime}, 5^{\prime}, 6^{\prime}, 7^{\prime}, 8^{\prime}\right)$

BB $(P 1)=H\left(1,8,4^{\prime}, 5^{\prime}\right)$

BB $(P 2)=H(2,3,4,5,6,7$

$\left.1^{\prime}, 2^{\prime}, 3^{\prime}, 6^{\prime}, 7^{\prime}, 8^{\prime}\right)$

BB $(P 3)=H\left(9^{\prime}, 10\right)$

Figure 7. (a) The comparison of $400 \mathrm{MHz}{ }^{1} \mathrm{H}-\mathrm{NMR}$ spectra of $2.25 \mathrm{mM}$ of pure anthracene (A) (at the top), $2.25 \mathrm{mM}$ of pure 9-bromoanthracene (B) (at the bottom) and their mixture (in the middle) before (upper black spectrum) and after (lower blue spectrum) UV illumination $(\lambda=365 \mathrm{~nm})$ as well as $(\mathbf{b})$ the assignment of the spectral lines. S1-S5 and P1-P5 represent spectral lines of substrate and product respectively. AA, BB and AB correspond to the dimer of anthracene, dimer of 9-bromoanthracene and dimer of anthracene and 9-bromoanthracene, respectively. Samples were prepared in deuterated $\mathrm{CD}_{2} \mathrm{Cl}_{2}$ in the glove box.

When analyzing the data, we realized that apart from the creation of homodimers and mixed dimers there were some other reactions occurring that could not be tracked by NMR in a sense, that their resonances are low, and the integration is burdened with large errors. However, if we expect that the mass of the system (mass of substrates and products) is constant, then from the loss of the mass of the system, we can track the side product creations. To compensate for these side-reactions, we have assumed that all mass loss of $\mathbf{A}$, including the oxygenation effect, is responsible for the creation of unknown compound $\mathbf{X A}$ and similarly for $\mathbf{B}$ the $\mathbf{X B}$ compound is formed. The $\mathbf{X A}$ and $\mathbf{X B}$ concentration was calculated using such equations:

$$
\begin{gathered}
{[\mathrm{XA}]=[\mathrm{A}]_{0}+[\mathrm{AA}]_{0}+[\mathrm{AB}]_{0}-[\mathrm{A}]-[\mathrm{AA}]-[\mathrm{AB}],} \\
{[\mathrm{XB}]=[\mathrm{B}]_{0}+[\mathrm{BB}]_{0}+[\mathrm{AB}]_{0}-[\mathrm{B}]-[\mathrm{BB}]-[\mathrm{AB}]}
\end{gathered}
$$

where $\mathrm{A}_{0}, \mathrm{AA}_{0}, \mathrm{AB}_{0}$ and $\mathrm{B}_{0}$ stand for the initial concentrations. 

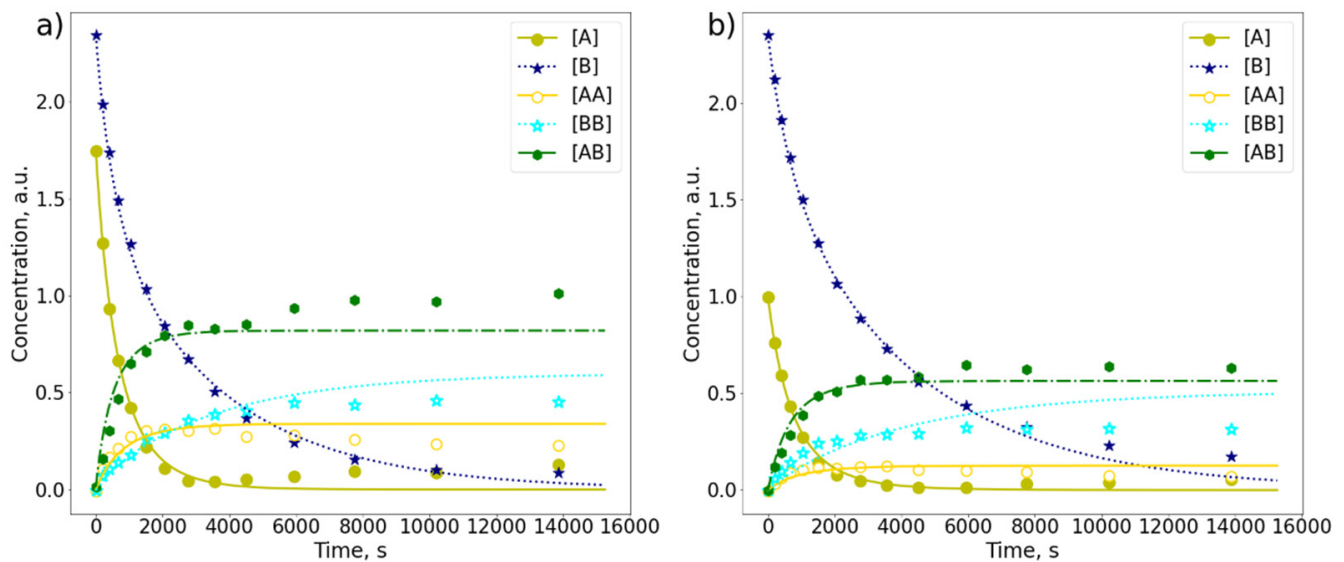

Figure 8. The comparison of photodimerization curves $(\lambda=365 \mathrm{~nm})$ derived from $400 \mathrm{MHz}{ }^{1} \mathrm{H}-\mathrm{NMR}$ spectra of anthracene (A) and 9-bromoanthracene (B) in the mixture with molar mixing ratios (a) 1:1.3 and (b) 1:2.3. Three dimmers are observed: AA, BB and AB.

It was also noticed that in some cases, for longer irradiation times, reactions are slightly reversible, which might be caused by the solvent, or by the changes in the temperature due to longer illumination times of up to few hours or by some other yet-unexplored effects. However, since it does not have a significant impact on the comparison of the kinetics of our compounds, it was decided to leave the investigation for further studies. Hence, for the simplicity of the model, such reversible reactions were not included in the calculations and the data presented in Figure 8a,b was fitted using the first $6000 \mathrm{~s}$ with the system of differential equations:

$$
\begin{gathered}
\frac{d[\mathrm{~A}]}{d t}=-k_{\mathrm{A}}[\mathrm{A}]-k_{\mathrm{AB}}[\mathrm{A}]^{\frac{1}{2}}[\mathrm{~B}]^{\frac{1}{2}}-k_{\mathrm{XA}}[\mathrm{A}] \\
\frac{d[\mathrm{~B}]}{d t}=-k_{\mathrm{B}}[\mathrm{B}]-k_{\mathrm{AB}}[\mathrm{A}]^{\frac{1}{2}}[\mathrm{~B}]^{\frac{1}{2}}-k_{\mathrm{XB}}[\mathrm{B}] \\
\frac{d[\mathrm{AA}]}{d t}=k_{\mathrm{A}} \frac{[\mathrm{A}]}{2} \\
\frac{d[\mathrm{BB}]}{d t}=k_{\mathrm{B}} \frac{[\mathrm{B}]}{2} \\
\frac{d[\mathrm{AB}]}{d t}=k_{\mathrm{AB}}[\mathrm{A}]^{\frac{1}{2}}[\mathrm{~B}]^{\frac{1}{2}}, \\
\frac{d[\mathrm{XA}]}{d t}=k_{\mathrm{XA}}[\mathrm{A}], \\
\frac{d[\mathrm{XB}]}{d t}=k_{\mathrm{XB}}[\mathrm{B}] .
\end{gathered}
$$

Here $k_{\mathrm{A}}, k_{\mathrm{B}}, k_{\mathrm{AB}}, k_{\mathrm{XA}}$ and $k_{\mathrm{XB}}$ are the kinetic constants for the reactions $\mathbf{A}+\mathbf{A} \rightarrow \mathbf{A A}$, $\mathbf{B}+\mathbf{B} \rightarrow \mathbf{B B}, \mathbf{A}+\mathbf{B} \rightarrow \mathbf{A B}, \mathbf{A} \rightarrow \mathbf{X A}$ and $\mathbf{B} \rightarrow \mathbf{X B}$, respectively. The calculated $k_{\mathrm{A}}, k_{\mathrm{B}}$ and $k_{\mathrm{AB}}$ values are gathered in Table 1 . In the case of the mixture, $k_{\mathrm{A}}$ and $k_{\mathrm{B}}$ values were higher when mixing molar ratio corresponded to the more comparable concentrations of $\mathbf{A}$ and $\mathbf{B}$. For instance, when the mixing ratio was $1: 1.3$ for $\mathbf{A}: \mathbf{B}, k_{\mathrm{A}}$ and $k_{\mathrm{B}}$ were equal to $5.01 \times 10^{-4} \mathrm{~s}^{-1}$ and $2.15 \times 10^{-4} \mathrm{~s}^{-1}$, respectively, while accordingly at mixing ratio of 1:2.3 the $k_{\mathrm{A}}$ and $k_{\mathrm{B}}$ values dropped to $3.23 \times 10^{-4} \mathrm{~s}^{-1}$ and $1.43 \times 10^{-4} \mathrm{~s}^{-1}$, respectively. However, the ratio $k_{\mathrm{A}} / k_{\mathrm{B}}$ remained the same and was equal to approximately 2 . The same ratio estimated from the measurements carried out in the solutions with only $\mathbf{A}$ or $\mathbf{B}$ was about 5 times larger. Nevertheless, the same trend was observed, confirming that $\mathbf{A}$ reacts faster than $\mathbf{B}$. Moreover, as we can see, the kinetic constant $k_{\mathrm{AB}}$ corresponding to the formation of the mixdimer $\mathbf{A B}$ remained the same for both studied mixtures. 
Table 1. Kinetic constants of photodimerization of anthracene (A) and 9-bromoanthracene (B) in separate samples and in the mixtures. Values $k_{\mathrm{A}}, k_{\mathrm{B}}$ and $k_{\mathrm{AB}}$ were calculated using a fitting procedure for the first $6000 \mathrm{~s}$ and correspond to reactions $\mathbf{A}+\mathbf{A} \rightarrow \mathbf{A A}, \mathbf{B}+\mathbf{B} \rightarrow \mathbf{B B}, \mathbf{A}+\mathbf{B} \rightarrow \mathbf{A B}$, respectively.

\begin{tabular}{cccc}
\hline Sample & $\boldsymbol{k}_{\mathrm{A}}, \mathbf{s}^{-\mathbf{1}}$ & $\boldsymbol{k}_{\mathbf{B}}, \mathbf{s}^{-\mathbf{1}}$ & $\boldsymbol{k}_{\mathrm{AB}}, \mathbf{s}^{-\mathbf{1}}$ \\
\hline $\mathbf{A}(4.5 \mathrm{mM})$ & $(2.8 \pm 0.03) \times 10^{-3}$ & - & - \\
\hline $\mathbf{B}(4.5 \mathrm{mM})$ & - & $(2.60 \pm 0.06) \times 10^{-4}$ & - \\
\hline Mixture of $\mathbf{A}: \mathbf{B}=1: 1.3$ & $(5.01 \pm 0.83) \times 10^{-4}$ & $(2.15 \pm 0.26) \times 10^{-4}$ & $(3.88 \pm 0.41) \times 10^{-4}$ \\
\hline Mixture of $\mathbf{A}: \mathbf{B}=1: 2.3$ & $(2.81 \pm 1.04) \times 10^{-4}$ & $(1.32 \pm 0.19) \times 10^{-4}$ & $(3.89 \pm 0.59) \times 10^{-4}$ \\
\hline
\end{tabular}

Finally, regarding the more comprehensive discussion of the obtained data, an important aspect has to be mentioned. When two different anthracene molecules $\mathbf{A}$ and $\mathbf{B}$ are involved in a photoreaction, two scenarios are possible: $\mathbf{A}^{*}+\mathbf{B} \rightarrow \mathbf{A B}$ or $\mathbf{A}+\mathbf{B}^{*} \rightarrow \mathbf{A B}$, where $\mathbf{A}^{*}$ and $\mathbf{B}^{*}$ stand for molecules in the excited electronic states. NMR spectra do not give enough information to determine which scenario takes place or dominates. In this context, the use of optical spectroscopy and quantum chemistry calculations could significantly support NMR. To conclude, the answer to this question requires more comprehensive studies which are beyond the scope of the present article.

\section{Materials and Methods}

\subsection{Samples}

The solution of anthracene (A) and 9-bromoanthracene $(\mathbf{B})$ were chosen for monitoring the photodimerization process. Both substrates were bought from Sigma Aldrich and dissolved in $\mathrm{CD}_{2} \mathrm{Cl}_{2}(99.6 \% \mathrm{D})$, which was purchased from Deutero $\mathrm{GmbH}$. An additional compound, anthraquinone, which was used for the confirmation of spectral lines when the oxygenation process was analyzed, was bought from TCI Chemicals. All chemicals were used as received from the supplier without any further purification. The NMR samples were prepared in a glove box under inert gas conditions. The samples of $0.48 \mathrm{~mL}$ volume were placed in $5 \mathrm{~mm}$ low pressure/vacuum (LPV) NMR tubes equipped with J. Young valves to avoid oxygenation, changes of the moisture content and evaporation of the solvent. Unless stated otherwise, the concentration of our substrates was either $4.5 \mathrm{mM}$ or $2.25 \mathrm{mM}$.

\subsection{UV Illumination}

UV illumination was performed by a $365 \mathrm{~nm}$ (9 nm FWHM) collimated LED (M365LP1-C4) with a beam diameter of $44 \mathrm{~mm}$ purchased from Thorlabs. It contained a $2.5 \mathrm{~mm} \times 2.5 \mathrm{~mm}$ mounted LED with a maximum power of $2000 \mathrm{~mW}$, and an irradiance of $21.0 \mu \mathrm{W} / \mathrm{mm}^{2}$ when operating at a $1700 \mathrm{~mA}$ maximum current. An approximate total beam power of collimated LED; however, it was reduced to $615 \mathrm{~mW}(1700 \mathrm{~mA})$ after passing through the aspheric collimation optic. During all experiments, the LED current was set to $700 \mathrm{~mA}$ using a T-cube LED driver (LEDD1B), also bought from Thorlabs. An NMR tube containing $480 \mu \mathrm{L}$ of the solution was placed $14 \mathrm{~cm}$ away from the LED's lens, resulting in the full illumination of the sample before each NMR measurement. The duration of UV irradiation varied from $60 \mathrm{~s}$ to $60 \mathrm{~min}$ depending on the stage and the reaction rate of the photodimerization process.

\subsection{NMR Experiment}

NMR experiments were carried out at room temperature on a VARIAN VNMRS Oxford AS400 NMR spectrometer operating at the resonance frequency of $400 \mathrm{MHz}$ for ${ }^{1} \mathrm{H}$ (magnetic field of 9.4 T) using an ASW dual-resonance broadband gradient NMR probe head. The ${ }^{1} \mathrm{H}-\mathrm{NMR}$ monitoring of each individual compound was performed at least twice as separate experiments to ensure that the experimental setup works in a repeatable manner. The signal of tetramethylsilane was used as a reference. The $90^{\circ}$ pulse length was $10.75 \mu \mathrm{s}$, and 8 scans were accumulated with a repetition delay of $40 \mathrm{~s}$. The spectral width 
was $12 \mathrm{ppm}$ with $16 \mathrm{k}$ points as the size of the FID. Relaxation times, $T_{1}$, were measured by the inversion recovery method. The NMR spectra were processed using TopSpin 4.0.7 software.

\subsection{Data Analysis}

The concentration of substrates and products in the investigated samples was deduced from the integrals of the best distinguishable ${ }^{1} \mathrm{H}-\mathrm{NMR}$ spectral lines measured after each UV illumination. Then, the reaction curves were derived showing the concentration dependence on total UV irradiation time, which corresponds to the reaction time since, the reaction occurs only during the illumination. The reaction law for one compound can be described by the following equation:

$$
\frac{d[\mathrm{C}]}{d t}=k[\mathrm{C}]^{x}
$$

where $k$ is the rate constant, $[\mathrm{C}]$ is the concentration of substrate $\mathrm{C}$ in the photodimerization reaction and $x$ refers to the reaction order with respect to the reactant $C$. All the fittings were performed using the Symfit library in Python [58]. The order of the reactions was established using data from single compound experiments. The fits of the reaction order from 0 to 3 were performed with a step of 0.1 followed by the analysis of the residual as a function of reaction order. The minimum value of the residual corresponded to the most probable reaction order with respect to the selected compound, as illumination conditions and sample.

\section{Conclusions}

Despite the recent progress in the photochemistry of anthracenes, the photosynthesis of novel materials is still a demanding task which necessitates a deeper understanding of the photochemistry of this class of aromatic compounds. Here, we demonstrate that the photoreactivity of different anthracenes can be investigated via NMR in a mixture. To the best of our knowledge, the kinetics of such mixtures has not been investigated so far. In the case of a mixture of anthracene (A) and 9-bromoanthracene (B), two homodimers $\mathbf{A A}$ and $\mathbf{B B}$, and one mixdimer $\mathbf{A B}$ were identified by ${ }^{1} \mathrm{H}$ NMR upon the UV irradiation. The ${ }^{1} \mathrm{H}$ NMR enables the monitoring of the photoreaction progress. This approach allows one to study the kinetics of three photoreactions simultaneously in the same solution, i.e., under exactly the same conditions. Thus, the relative reactivity obtained in this way is more informative. Specifically, the kinetics data show that the AB formation can be as fast as the AA formation, which is not obvious, as $\mathbf{B}$ contains bromide as a deactivating group. This shows that the mixdimers formation seems to be somehow favored over homodimers. This is important because as the mixdimer is predominant in comparison to the two homodimers, the photofabrication of materials based on the mixdimers can be greatly facilitated.

Finally, the presented approach can be treated as a methodology for the more comprehensive investigation of the photoreactivity of varying anthracenes, as we have evaluated the required experimental conditions and their influence on the photochemical reactions of anthracenes. In particular, oxygen can blur the picture of the kinetics, however, the adverse effect of oxygen can be included in the kinetic model, which improves the reliability of the kinetic data. The obtained knowledge opens up an easy and reliable route for further development of the in-situ illuminated-NMR monitoring system, which requires a more sophisticated illumination setup in terms of identical experimental conditions. Moreover, the integration of the in-situ illuminated-NMR with other spectroscopic methods, for example, fluorescence, can be a powerful tool that supports the NMR investigation of the photodimerization of varying anthracenes.

Supplementary Materials: The following are available online, Figure S1: determination of photodimerization reaction order, Figure S2: the effect of illuminated volume of the sample, Figure S3: 
crystallization of the photodimerization product, Scheme S1: The general scheme of photooxygenation, Figure S4: ${ }^{1} \mathrm{H}-\mathrm{NMR}$ spectra of anthraquinone, Figure S5: Photodimerization of anthracenes A and B under inert gas atmosphere, Figure S6: the comparison of photodimerization curves of $\mathbf{A}$ and B in separate samples, and in the mixture when fitting was done using the first $6000 \mathrm{~s}$, and the model included the product of oxygenation as well as unidentified products, Figure S7: ${ }^{1} \mathrm{H}-\mathrm{NMR}$ spectra of $\mathbf{A}$ and $\mathbf{B}$ in separate samples, and in the mixture using benzene as a solvent, Table S1: kinetic constants $k_{\mathrm{XA}}, k_{\mathrm{XB}}$ and $k_{\mathrm{BO}}$.

Author Contributions: Conceptualization, T.R.; Data curation, M.U.; Formal analysis, M.U.; Investigation, K.K.; Methodology, K.K. and M.P.; Resources, K.K., A.M. and M.P.; Software, M.U.; Supervision, T.R.; Validation, M.P.; Visualization, K.K., M.U. and A.M.; Writing-original draft, K.K. and T.R.; Writing-review \& editing, M.U., A.M., M.P. and T.R. All authors have read and agreed to the published version of the manuscript.

Funding: This publication is part of a project that has received funding from the European Union's Horizon 2020 research and innovation program under the Marie Skłodowska-Curie grant agreement No. 847413. Scientific work published as part of an international co-financed project founded from the program of the Minister of Science and Higher Education entitled "PMW" in the years 2020-2024; agreement no. 5005/H2020-MSCA-COFUND/2019/2.

Institutional Review Board Statement: Not applicable.

Informed Consent Statement: Not applicable.

Data Availability Statement: The raw dataset is published in zenodo.org and is available at: https:/ / doi.org/10.5281/zenodo.5543208.

Conflicts of Interest: The authors declare no conflict of interest.

\section{References}

1. Clar, E. Vorschläge Zur Nomenklatur Kondensierter Ringsysteme (Aromatische Kohlenwasserstoffe, XXVI. Mitteil.). Ber. Dtsch. Chem. Ges. 1939, 72, 2137-2139. [CrossRef]

2. Tönshoff, C.; Bettinger, H.F. Pushing the Limits of Acene Chemistry: The Recent Surge of Large Acenes. Chem. Eur. J. 2021, 27, 3193-3212. [CrossRef]

3. Brancart, J.; Van Damme, J.; Du Prez, F.; Van Assche, G. Substituent Effect on the Thermophysical Properties and Thermal Dissociation Behaviour of 9-Substituted Anthracene Derivatives. Phys. Chem. Chem. Phys. 2021, 23, 2252-2263. [CrossRef]

4. Müller, M.; Ahrens, L.; Brosius, V.; Freudenberg, J.; Bunz, U.H.F. Unusual Stabilization of Larger Acenes and Heteroacenes. J. Mater. Chem. C 2019, 7, 14011-14034. [CrossRef]

5. Ye, Q.; Chi, C. Recent Highlights and Perspectives on Acene Based Molecules and Materials. Chem. Mater. 2014, 26, 4046-4056. [CrossRef]

6. Dong, S.; Ong, A.; Chi, C. Photochemistry of Various Acene Based Molecules. J. Photochem. Photobiol. C Photochem. Rev. 2019, 38, 27-46. [CrossRef]

7. Baviera, G.S.; Donate, P.M. Recent Advances in the Syntheses of Anthracene Derivatives. Beilstein J. Org. Chem. 2021, 17, 2028-2050. [CrossRef] [PubMed]

8. Yoshizawa, M.; Klosterman, J.K. Molecular Architectures of Multi-Anthracene Assemblies. Chem. Soc. Rev. 2014, 43, 1885-1898. [CrossRef]

9. Bouas-Laurent, H.; Castellan, A.; Desvergne, J.-P.; Lapouyade, R. Photodimerization of Anthracenes in Fluid Solutions: (Part 2) Mechanistic Aspects of the Photocycloaddition and of the Photochemical and Thermal Cleavage. Chem. Soc. Rev. 2001, 30, 248-263. [CrossRef]

10. Breton, G.W.; Vang, X. Photodimerization of Anthracene. J. Chem. Educ. 1998, 75, 81. [CrossRef]

11. Fidder, H.; Lauer, A.; Freyer, W.; Koeppe, B.; Heyne, K. Photochemistry of Anthracene-9,10-Endoperoxide. J. Phys. Chem. A 2009, 113, 6289-6296. [CrossRef]

12. Zhu, J.; Zou, J.; Zhang, J.; Sun, Y.; Dong, X.; Zhang, Q. An Anthracene Functionalized BODIPY Derivative with Singlet Oxygen Storage Ability for Photothermal and Continuous Photodynamic Synergistic Therapy. J. Mater. Chem. B 2019, 7, $3303-3309$. [CrossRef]

13. Fudickar, W.; Linker, T. Reversible Photooxygenation of Alkynylanthracenes: Chemical Generation of Singlet Oxygen under Very Mild Conditions. Chem. Eur. J. 2011, 17, 13661-13664. [CrossRef]

14. Geroldinger, G.; Tonner, M.; Fudickar, W.; De Sarkar, S.; Dighal, A.; Monzote, L.; Staniek, K.; Linker, T.; Chatterjee, M.; Gille, L. Activation of Anthracene Endoperoxides in Leishmania and Impairment of Mitochondrial Functions. Molecules 2018, 23, 1680. [CrossRef] 
15. Klaper, M.; Wessig, P.; Linker, T. Base Catalysed Decomposition of Anthracene Endoperoxide. Chem. Commun. 2016, $52,1210-1213$. [CrossRef]

16. Khurana, B.; Gierlich, P.; Meindl, A.; Gomes-da-Silva, L.C.; Senge, M.O. Hydrogels: Soft Matters in Photomedicine. Photochem. Photobiol. Sci. 2019, 18, 2613-2656. [CrossRef] [PubMed]

17. Oliveira, M.S.; Chorociejus, G.; Angeli, J.P.F.; Vila Verde, G.; Aquino, G.L.B.; Ronsein, G.E.; De Oliveira, M.C.B.; Barbosa, L.F.; Medeiros, M.H.G.; Greer, A.; et al. Heck Reaction Synthesis of Anthracene and Naphthalene Derivatives as Traps and Clean Chemical Sources of Singlet Molecular Oxygen in Biological Systems. Photochem. Photobiol. Sci. 2020, 19, 1590-1602. [CrossRef]

18. Van Damme, J.; Du Prez, F. Anthracene-Containing Polymers toward High-End Applications. Prog. Polym. Sci. 2018, 82, 92-119. [CrossRef]

19. Kislyak, A.; Frisch, H.; Gernhardt, M.; Van Steenberge, P.H.M.; D’Hooge, D.R.; Barner-Kowollik, C. Time-Dependent Differential and Integral Quantum Yields for Wavelength-Dependent [4+4] Photocycloadditions. Chem. Eur. J. 2020, 26, 478-484. [CrossRef] [PubMed]

20. Slifkin, M.A. Charge Transfer and Excimer Formation. Nature 1963, 200, 766-767. [CrossRef]

21. Das, A.; Danao, A.; Banerjee, S.; Raj, A.M.; Sharma, G.; Prabhakar, R.; Srinivasan, V.; Ramamurthy, V.; Sen, P. Dynamics of Anthracene Excimer Formation within a Water-Soluble Nanocavity at Room Temperature. J. Am. Chem. Soc. 2021, 143, 2025-2036. [CrossRef] [PubMed]

22. Applequist, D.E.; Litle, R.L.; Friedrich, E.; Wall, R.E. Anthracene Photodimers. I. Elimination and Substitution Reactions of the Photodimer of 9-Bromoanthracene1. J. Am. Chem. Soc. 1959, 81, 452-456. [CrossRef]

23. Arumugam, S.; Vutukuri, D.R.; Thayumanavan, S.; Ramamurthy, V. A Styrene Based Water Soluble Polymer as a Reaction Medium for Photodimerization of Aromatic Hydrocarbons in Water. J. Photochem. Photobiol. A Chem. 2007, 185, 168-171. [CrossRef]

24. Rao, M.; Wu, W.; Yang, C. Effects of Temperature and Host Concentration on the Supramolecular Enantiodifferentiating [4 + 4] Photodimerization of 2-Anthracenecarboxylate through Triplet-Triplet Annihilation Catalyzed by Pt-Modified Cyclodextrins. Molecules 2019, 24, 1502. [CrossRef]

25. Rao, M.; Wu, W.; Yang, C. Recent Progress on the Enantioselective Excited-State Photoreactions by Pre-Arrangement of Photosubstrate(s). Green Synth. Catal. 2021, 2, 131-144. [CrossRef]

26. Geiger, T.; Haupt, A.; Maichle-Mössmer, C.; Schrenk, C.; Schnepf, A.; Bettinger, H.F. Synthesis and Photodimerization of 2- and 2,3-Disubstituted Anthracenes: Influence of Steric Interactions and London Dispersion on Diastereoselectivity. J. Org. Chem. 2019, 84, 10120-10135. [CrossRef]

27. Takaguchi, Y.; Tajima, T.; Yanagimoto, Y.; Tsuboi, S.; Ohta, K.; Motoyoshiya, J.; Aoyama, H. Self-Assembly and Regioselective Photodimerization of Anthracene Having a Dendritic Substituent. Org. Lett. 2003, 5, 1677-1679. [CrossRef]

28. Maturi, M.M.; Fukuhara, G.; Tanaka, K.; Kawanami, Y.; Mori, T.; Inoue, Y.; Bach, T. Enantioselective [4+4] Photodimerization of Anthracene-2,6-Dicarboxylic Acid Mediated by a C2-Symmetric Chiral Template. Chem. Commun. 2016, 52, 1032-1035. [CrossRef]

29. Lamm, J.-H.; Glatthor, J.; Weddeling, J.-H.; Mix, A.; Chmiel, J.; Neumann, B.; Stammler, H.-G.; Mitzel, N.W. PolyalkynylanthracenesSyntheses, Structures and Their Behaviour towards UV Irradiation. Org. Biomol. Chem. 2014, 12, 7355-7365. [CrossRef]

30. Kan, L.; Cheng, H.; Li, B.; Zhang, X.; Wang, Q.; Wei, H.; Ma, N. Anthracene Dimer Crosslinked Polyurethanes as Mechanoluminescent Polymeric Materials. New J. Chem. 2019, 43, 2658-2664. [CrossRef]

31. Grossmann, L.; King, B.T.; Reichlmaier, S.; Hartmann, N.; Rosen, J.; Heckl, W.M.; Björk, J.; Lackinger, M. On-Surface Photopolymerization of Two-Dimensional Polymers Ordered on the Mesoscale. Nat. Chem. 2021, 13, 730-736. [CrossRef] [PubMed]

32. Li, Y.; Goswami, M.; Zhang, Y.; Liu, T.; Zhang, J.; Kessler, M.R.; Wang, L.; Rios, O. Combined Light- and Heat-Induced Shape Memory Behavior of Anthracene-Based Epoxy Elastomers. Sci. Rep. 2020, 10, 20214. [CrossRef] [PubMed]

33. Wang, Y.; Fang, D.; Fu, T.; Ali, M.U.; Shi, Y.; He, Y.; Hu, Z.; Yan, C.; Mei, Z.; Meng, H. Anthracene Derivative Based Multifunctional Liquid Crystal Materials for Optoelectronic Devices. Mater. Chem. Front. 2020, 4, 3546-3555. [CrossRef]

34. Chen, M.; Yan, L.; Zhao, Y.; Murtaza, I.; Meng, H.; Huang, W. Anthracene-Based Semiconductors for Organic Field-Effect Transistors. J. Mater. Chem. C 2018, 6, 7416-7444. [CrossRef]

35. Tümay, S.O.; Irani-Nezhad, M.H.; Khataee, A. Multi-Anthracene Containing Fluorescent Probe for Spectrofluorimetric Iron Determination in Environmental Water Samples. Spectrochim. Acta Part A Mol. Biomol. Spectrosc. 2021, 248, 119250. [CrossRef] [PubMed]

36. Díaz-Moscoso, A.; Ballester, P. Light-Responsive Molecular Containers. Chem. Commun. 2017, 53, 4635-4652. [CrossRef]

37. Saura, A.V.; Marín, M.J.; Burguete, M.I.; Russell, D.A.; Galindo, F.; Luis, S.V. The Synthesis of New Fluorescent Bichromophoric Compounds as Ratiometric PH Probes for Intracellular Measurements. Org. Biomol. Chem. 2015, 13, 7736-7749. [CrossRef] [PubMed]

38. Duprey, J.-L.H.A.; Bassani, D.M.; Hyde, E.I.; Jonusauskas, G.; Ludwig, C.; Rodger, A.; Spencer, N.; Vyle, J.S.; Wilkie, J.; Zhao, Z.-Y.; et al. Rationalisation of a Mechanism for Sensing Single Point Variants in Target DNA Using Anthracene-Tagged Base Discriminating Probes. Org. Biomol. Chem. 2018, 16, 6576-6585. [CrossRef]

39. Soylemez, S.; Goker, S.; Toppare, L. A Newly Designed Anthracene and Isoindigo Based Polymer: Synthesis\{,\} Electrochemical Characterization and Biosensor Applications. New J. Chem. 2019, 43, 13979-13984. [CrossRef]

40. Zhou, W.; Fang, Y.; Wu, X.; Han, Y.; Yang, J.; Shen, L.; Song, Y. Anthracene Derivatives as Broadband Nonlinear Optical Materials: Nonlinear Absorption and Excited-State Dynamics Analysis. RSC Adv. 2020, 10, 19974-19981. [CrossRef] 
41. Zhou, W.; Chen, Y.; Yu, Q.; Li, P.; Chen, X.; Liu, Y. Photo-Responsive Cyclodextrin/Anthracene/Eu3 ${ }^{+}$Supramolecular Assembly for a Tunable Photochromic Multicolor Cell Label and Fluorescent Ink. Chem. Sci. 2019, 10, 3346-3352. [CrossRef]

42. Pitzer, L.; Schäfers, F.; Glorius, F. Rapid Assessment of the Reaction-Condition-Based Sensitivity of Chemical Transformations. Angew. Chem. Int. Ed. 2019, 58, 8572-8576. [CrossRef] [PubMed]

43. Paululat, T.; Rabe, M.; Berdnikova, D.V. Modification of an NMR Probe for Monitoring of Photoreactions. J. Magn. Reson. 2021, 327, 106990. [CrossRef]

44. Dobkowski, J.; Gorski, A.; Kijak, M.; Pietrzak, M.; Redeckas, K.; Vengris, M. Combined Picosecond Time-Resolved UV-Vis and NMR Techniques Used for Investigation of the Excited State Intramolecular Triplet-Triplet Energy Transfer. J. Phys. Chem. A 2019, 123, 6978-6985. [CrossRef] [PubMed]

45. Gołowicz, D.; Kazimierczuk, K.; Urbańczyk, M.; Ratajczyk, T. Monitoring Hydrogenation Reactions Using Benchtop 2D NMR with Extraordinary Sensitivity and Spectral Resolution. ChemistryOpen 2019, 8, 196-200. [CrossRef] [PubMed]

46. Gomes, B.F.; Lobo, C.M.S.; Colnago, L.A. Monitoring Electrochemical Reactions in Situ with Low Field NMR: A Mini-Review. Appl. Sci. 2019, 9, 498. [CrossRef]

47. Skubi, K.L.; Swords, W.B.; Hofstetter, H.; Yoon, T.P. LED-NMR Monitoring of an Enantioselective Catalytic [2 + 2] Photocycloaddition. ChemPhotoChem 2020, 4, 685-690. [CrossRef]

48. Andrade, M.A.; Martins, L.M.D.R.S. New Trends in C-C Cross-Coupling Reactions: The Use of Unconventional Conditions. Molecules 2020, 25, 5506. [CrossRef] [PubMed]

49. Chanmungkalakul, S.; Ervithayasuporn, V.; Boonkitti, P.; Phuekphong, A.; Prigyai, N.; Kladsomboon, S.; Kiatkamjornwong, S. Anion Identification Using Silsesquioxane Cages. Chem. Sci. 2018, 9, 7753-7765. [CrossRef]

50. Kislyak, A.; Kodura, D.; Frisch, H.; Feist, F.; Van Steenberge, P.H.M.; Barner-Kowollik, C.; D’Hooge, D.R. A Holistic Approach for Anthracene Photochemistry Kinetics. Chem. Eng. J. 2020, 402, 126259. [CrossRef]

51. Rutnakornpituk, M.; Ngamdee, P. Surface and Mechanical Properties of Microporous Membranes of Poly(Ethylene Glycol)Polydimethylsiloxane Copolymer/Chitosan. Polymer 2006, 47, 7909-7917. [CrossRef]

52. Han, D.; Lu, H.; Li, W.; Li, Y.; Feng, S. Light- and Heat-Triggered Reversible Luminescent Materials Based on Polysiloxanes with Anthracene Groups. RSC Adv. 2017, 7, 56489-56495. [CrossRef]

53. Brancart, J.; Van Damme, J.; Du Prez, F.; Van Assche, G. Thermal Dissociation of Anthracene Photodimers in the Condensed State: Kinetic Evaluation and Complex Phase Behaviour. Phys. Chem. Chem. Phys. 2020, 22, 17306-17313. [CrossRef]

54. Huynh, V.N.; Leitner, M.; Bhattacharyya, A.; Uhlstein, L.; Kreitmeier, P.; Sakrausky, P.; Rehbein, J.; Reiser, O. Diels-Alder Reactions and Electrophilic Substitutions with Atypical Regioselectivity Enable Functionalization of Terminal Rings of Anthracene. Commun. Chem. 2020, 3, 158. [CrossRef]

55. Nitschke, P.; Lokesh, N.; Gschwind, R.M. Combination of Illumination and High Resolution NMR Spectroscopy: Key Features and Practical Aspects, Photochemical Applications, and New Concepts. Prog. Nucl. Magn. Reson. Spectrosc. 2019, 114-115, 86-134. [CrossRef] [PubMed]

56. Kuprov, I.; Hore, P.J. Uniform Illumination of Optically Dense NMR Samples. J. Magn. Reson. 2004, 171, 171-175. [CrossRef] [PubMed]

57. Pietrzak, M.; Dobkowski, J.; Gorski, A.; Gawinkowski, S.; Kijak, M.; Luboradzki, R.; Hansen, P.E.; Waluk, J. Arresting Consecutive Steps of a Photochromic Reaction: Studies of $\beta$-Thioxoketones Combining Laser Photolysis with NMR Detection. Phys. Chem. Chem. Phys. 2014, 16, 9128-9137. [CrossRef]

58. Roelfs, M.; Kroon, P.C. TBuLi/Symfit: Symfit 0.5.3; Zenodo: Genève, Switzerland, 2020. [CrossRef] 